\title{
Upstairs Walking Speed Distributions on a Long Stairway
}

\author{
Tobias Kretz ${ }^{1}$, Anna Grünebohm ${ }^{1}$, Andreas Kessel, Hubert Klüpfel ${ }^{2}$, \\ Tim Meyer-König ${ }^{2}$, and Michael Schreckenberg ${ }^{1}$ \\ ${ }^{1}$ Physik von Transport und Verkehr, \\ Universität Duisburg-Essen, \\ 47057 Duisburg, Germany \\ ${ }^{2}$ TraffGo HT GmbH, 47058 Duisburg
}

\{kretz,gruenebohm,schreckenberg\}@traffic.uni-duisburg.de $\{$ kluepfel,m-k\}@traffgo-ht.com

September 26, 2006

\begin{abstract}
In this work results from an examination of upstairs walking speeds at the outer stairway of the Dutch pavilion at the Expo 2000 in Hannover are presented. The distribution of horizontal walking speeds exhibits a maximum between 0.4 and $0.5 \mathrm{~m} / \mathrm{s}$, depending on the local density. To underline the need to measure walking speeds on long stairways if one wants to predict tavelling times on long stairways, these results are compared to a second study of walking speeds on a short stair. The main result of that measurement is, that some people actually accelerate when walking upward a short stairway, while such a phenomenon could neither be observed for downward motion on the short stairway nor for upward motion on the long stairway. The mean upward walking speed on the short stairway was found to be roughly twice as large as the one on the long stairway, which corresponds to the data found in the literature. Both studies were done by digitally filming the walking persons and evaluating the resulting material frame by frame for the walking times. Together the results suggest, that the speed on stairs does not only vary greatly depending on the length of the stairway, but also that there is no common scaling factor for the speed on stairs in dependence of the length of the stairway for the whole population. This has consequences e.g. for the construction of simulation models.
\end{abstract}

\section{Introduction}

It is equally difficult as necessary to get data of upstairs walking speed distributions on long stairs. It is difficult as nowadays there do exist only few really long stairs without 
parallel elevators. If there is an elevator as an alternative to walking a long stair one has fewer people deciding to walk the stairs. And those who do so are a selection of the whole population of which one can assume to be physically fitter than the average of the population. It is on the other hand necessary to get data from long stairs as in cases of emergency no elevators are available and therefore sometimes long stairs have to be walked. Even downstairs evacuation in high-rise-buildings is often planned as "phased evacuation" partly since many people are not able to move downward a large number of stairs. Still the problem is not that urgent in most buildings, as typically people only have to walk downstairs. Therefore endurance abilities of the occupants only are of minor importance. However there are structures where walking upstairs several floors can become necessary. On board e.g. of cruise ships there are situations where a non-negligible fraction of passengers linger at lower decks. Therefore they would have to walk several floors upstairs to reach the exits and life-boats. But also certain big underground garages or large underground stations would fall into this category. Here endurance does play a role and empirical data from short stairs is only of limited use for calculating walking times. Therefore the aim of this study was to find out the distribution of walking speeds on a stairway that is that long that even trained people would consider climbing it a matter of endurance.

\section{Scenario, Methods and Materials}

The Dutch pavilion at the Expo 2000 in Hannover, Germany (English spelling: "Hanover") has had elevators, yet they were located some distance away from the entrance of the stairs. In addition the chance to oversee the area from some height might have attracted some people to walk the stairs instead of taking the elevator. The comparatively long stairs (total height 35.8 meters) were on the outside where quite good observation conditions were given. Figure 1 shows that the observation region was shortly below the roof, implying that the observed persons already had climbed approximately $25 \mathrm{~m}$ high before their walking speeds were measured. The stair steps had (respectively have) a tread of $27.0 \mathrm{~cm}$ and a riser of $19.0 \mathrm{~cm}$. This implies an angle of inclination of $35.1^{\circ}$. The stairs had a closed box design, and the railing a round shape that could be encompassed. To summarize these details: a special building code was raised for the Expo 2000 and the stairway in concern met all of these standards concerning riser, tread, slippery resistance, used materials, etc..

An objective measurement of the density was not possible. Therefore, each measurement was subjectively assigned by visual judgement to one of three categories based upon the potential influence of other nearby persons. These categories were:

- The individual in focus was walking obviously uninfluenced by anyone else. (Category A)

- Few people standing or moving around the individual in focus, but there were only small or even no visible influences from one to another. (Category B)

- High density situation, each person clearly influenced the others in the surrounding. (Category C) 


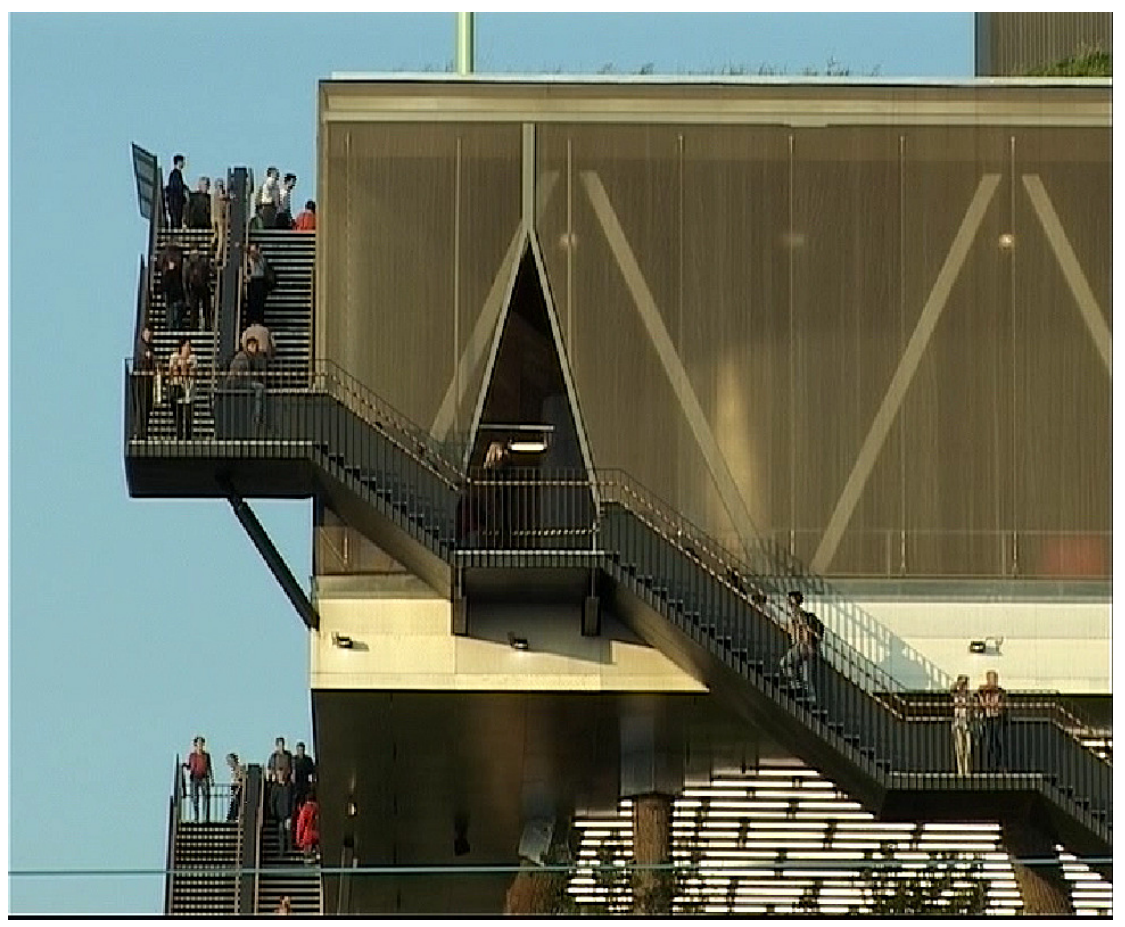

Figure 1: The walking times were measured at the part of the 18 stairs at the right to the triangle-shaped door (platform to platform). The whole stairway had this design of an alternation of stairs and platforms. 
The visitors moving upward were filmed at a frame rate of 25 frames per second and the recordings were evaluated later on a frame by frame basis. One person did all the evaluation. For a sample of persons however the discrepancy to the results of another person was checked: it was never larger than two frames ( 0.08 seconds), mostly one or no frame.

The comparison study on a short stairway took place at the World Team Cup tennis tournament 2004 at the Rochusclub in Düsseldorf. A total of 85 spectators walking upward and downward a stair were filmed and their walking speeds were measured. People obviously doing anything else than exclusively walking were not taken into the statistics. The details of the stairs were as follows: 12 steps with a tread of $36.7 \mathrm{~cm}$ and a riser height of $15.0 \mathrm{~cm}$, the stairs were covered with a felt (or felt-like) carpet. The camera was the same as for the first study.

\subsection{Weather Conditions}

The recordings of the Expo study took place at the 31 st July 2000 at about 8:30 pm. The temperatures at that day varied between $14.1^{\circ} \mathrm{C}$ and $20.6^{\circ} \mathrm{C}$ with an average of $15.9^{\circ} \mathrm{C}$. The day was mostly cloudy however it did not rain throughout the day. There was a total of 4.5 hours of sunshine during the evening hours when the recordings took place and it was almost windless (DWD, 2000). Besides these information, the weather conditions at the time of the recording can probably best be estimated by looking at figure 1, which is a frame taken from the footage that was actually used for evaluation. So, the weather conditions can be assumed to have been considered very comfortable by most people.

During the recordings for the comparison study on a short stair (May 19th, 2004) there were very comfortable conditions as well: approximately $24^{\circ} \mathrm{C}$, good lighting conditions and no rain.

\section{Results}

\subsection{The "Expo Stairway"}

The walking speeds of 485 individuals were measured. The mean, meadian, maximum and minimum speeds within each category are listed in table 1 . The relations between the types of speed are $v_{\text {vertical }} \approx 0.704 \cdot v_{\text {horizontal }}$ and $v_{\text {slope }} \approx 1.223 \cdot v_{\text {horizontal }}$. In more detail, figures 2, 3, and 4 show the distributions for the horizontal speed.

\subsection{Comparison Study on Short Stairs}

At the World Team Cup tennis tournament 2004 at the Rochusclub in Düsseldorf. The results are shown in table 2. The three largest speeds upstairs are larger than the largest speed downstairs. As well are the ten largest speeds upstairs larger than the third largest downstairs. For categories $\mathrm{B}$ and $\mathrm{C}$ even the mean walking speeds are larger upstairs than downstairs. This confirms that on shorter stairs one can sometimes watch people, 


\begin{tabular}{l|ccc} 
& Category A & Category B & Category C \\
\hline \# of persons & 73 & 390 & 23 \\
\hline Mean horizontal speed & 0.423 & 0.382 & 0.359 \\
Standard deviation & 0.130 & 0.075 & 0.040 \\
Median horizontal speed & 0.410 & 0.374 & 0.349 \\
Minimum horizontal speed & 0.22 & 0.13 & 0.27 \\
Maximum horizontal speed & 1.27 & 1.15 & 0.43 \\
\hline Mean vertical speed & 0.298 & 0.269 & 0.253 \\
Standard deviation & 0.091 & 0.053 & 0.028 \\
Median vertical speed & 0.289 & 0.263 & 0.246 \\
Minimum vertical speed & 0.15 & 0.09 & 0.25 \\
Maximum vertical speed & 0.89 & 0.81 & 0.30 \\
\hline Mean slope speed & 0.517 & 0.468 & 0.439 \\
Standard deviation & 0.159 & 0.091 & 0.048 \\
Median slope speed & 0.502 & 0.457 & 0.427 \\
Minimum slope speed & 0.27 & 0.16 & 0.43 \\
Maximum slope speed & 1.55 & 1.40 & 0.52 \\
\hline Mean \# of stairs per second & 1.567 & 1.416 & 1.331 \\
Standard deviation & 0.481 & 0.277 & 0.147 \\
Median \# of stairs per second & 1.520 & 1.385 & 1.293 \\
Minimum \# of stairs per second & 0.82 & 0.48 & 1.30 \\
Maximum \# of stairs per second & 4.69 & 4.25 & 1.59 \\
\hline
\end{tabular}

Table 1: Basic Results. All speeds and standard deviations in $\mathrm{m} / \mathrm{s}$ respectively stairs/s.

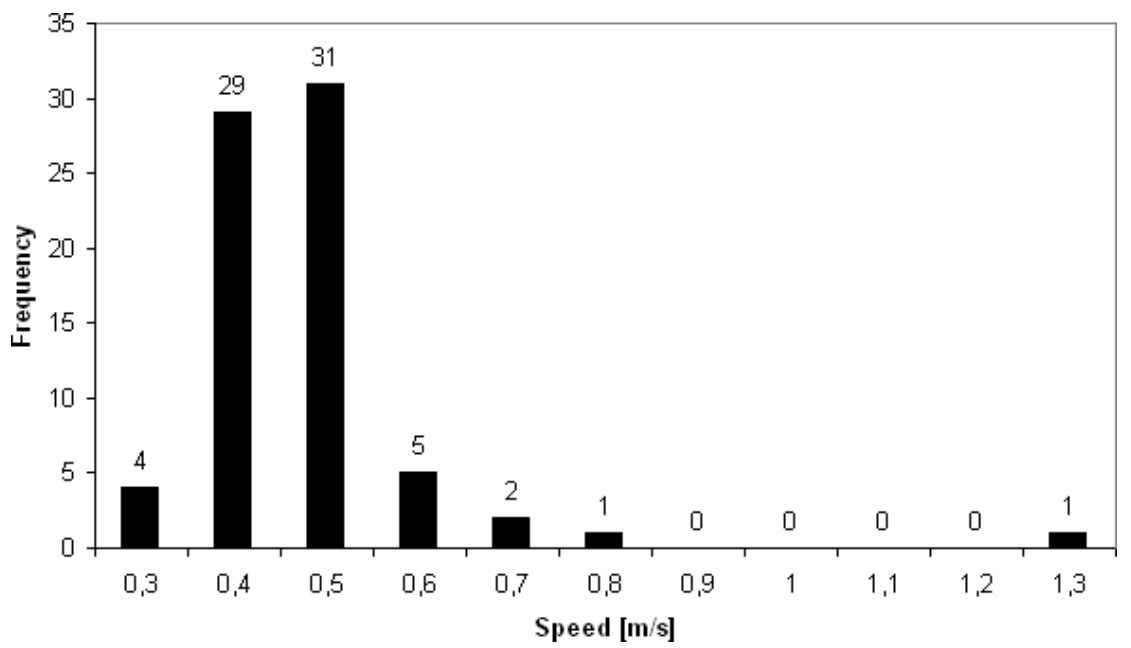

Figure 2: Histogram of the horizontal speeds for category A. 


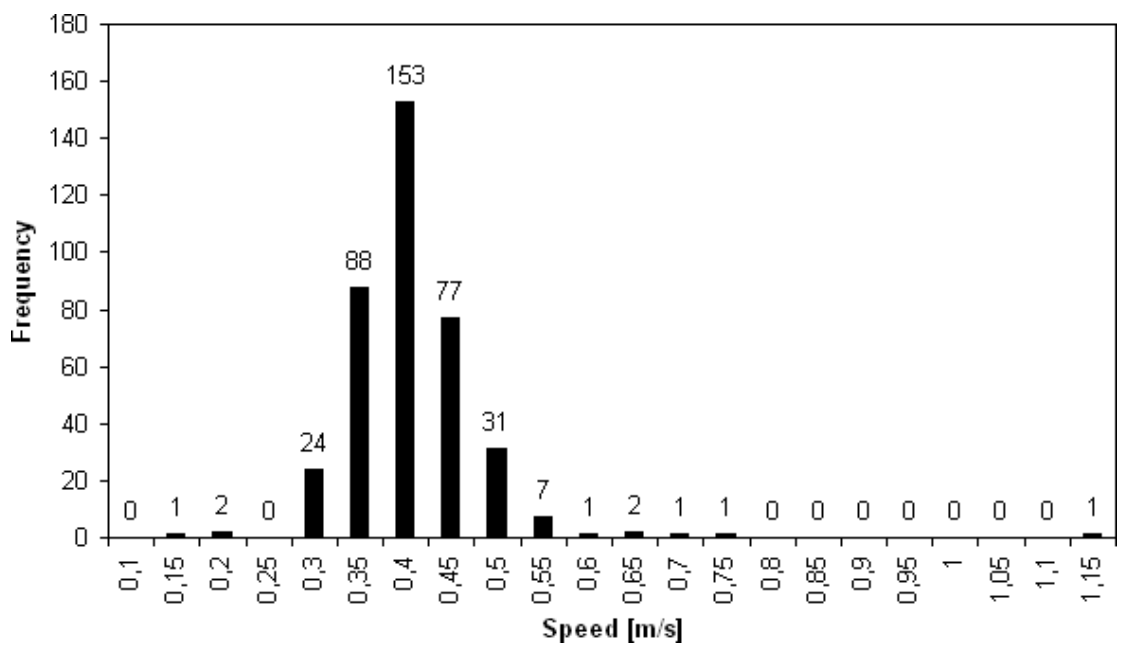

Figure 3: Histogram of the horizontal speeds for category B.

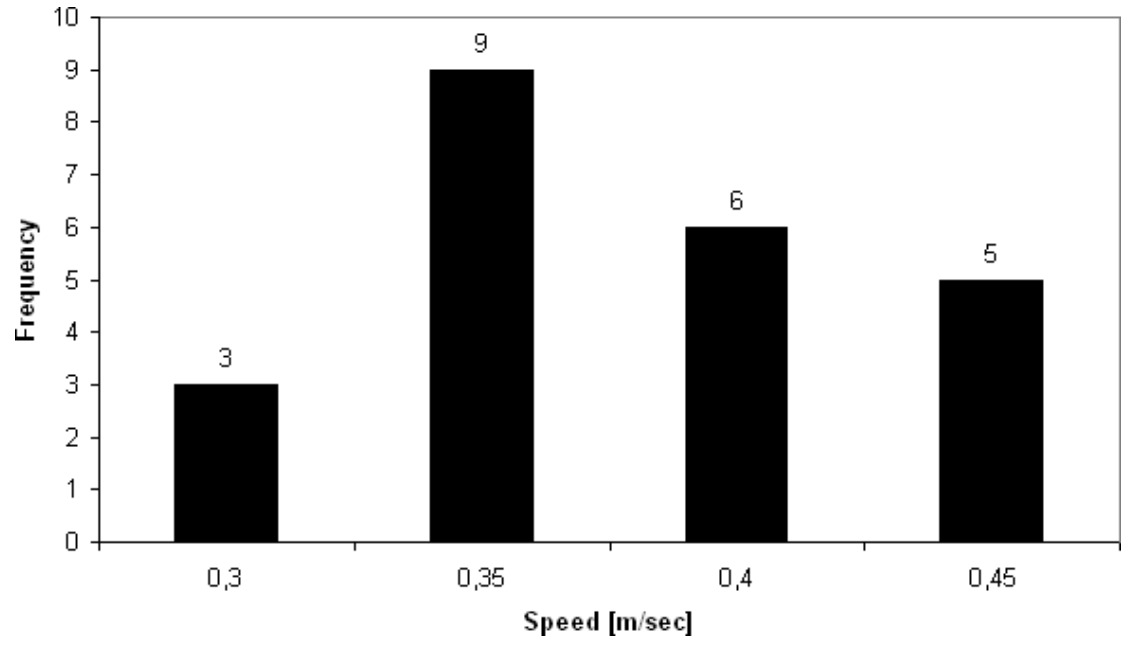

Figure 4: Histogram of the horizontal speeds for category C. 


\begin{tabular}{l|cccc} 
& Category A & Category B & Category C & All \\
\hline \# of persons upstairs & 10 & 62 & 19 & 91 \\
\# of persons downstairs & 6 & 38 & 38 & 82 \\
\hline Mean upstairs & $0.78 \mathrm{~m} / \mathrm{s}$ & $0.70 \mathrm{~m} / \mathrm{s}$ & $0.71 \mathrm{~m} / \mathrm{s}$ & $0.71 \mathrm{~m} / \mathrm{s}$ \\
Mean downstairs & $0.83 \mathrm{~m} / \mathrm{s}$ & $0.63 \mathrm{~m} / \mathrm{s}$ & $0.65 \mathrm{~m} / \mathrm{s}$ & $0.65 \mathrm{~m} / \mathrm{s}$ \\
Minimum upstairs & $0.13 \mathrm{~m} / \mathrm{s}$ & $0.41 \mathrm{~m} / \mathrm{s}$ & $0.53 \mathrm{~m} / \mathrm{s}$ & $0.13 \mathrm{~m} / \mathrm{s}$ \\
Minimum downstairs & $0.54 \mathrm{~m} / \mathrm{s}$ & $0.38 \mathrm{~m} / \mathrm{s}$ & $0.21 \mathrm{~m} / \mathrm{s}$ & $0.21 \mathrm{~m} / \mathrm{s}$ \\
Maximum upstairs & $1.43 \mathrm{~m} / \mathrm{s}$ & $1.86 \mathrm{~m} / \mathrm{s}$ & $1.29 \mathrm{~m} / \mathrm{s}$ & $1.86 \mathrm{~m} / \mathrm{s}$ \\
Maximum downstairs & $1.33 \mathrm{~m} / \mathrm{s}$ & $0.96 \mathrm{~m} / \mathrm{s}$ & $1.39 \mathrm{~m} / \mathrm{s}$ & $1.39 \mathrm{~m} / \mathrm{s}$
\end{tabular}

Table 2: Horizontal walking speeds on a short stair.

especially young people, accelerating when walking upstairs compared to them walking on horizontal ground or downstairs. Therefore the measurement of walking speeds on short stairways can not easily be used to predict walking times on longer stairways.

The reason why for category $\mathrm{C}$ the mean velocities are slightly larger than for category B may be due to people feeling urged to move on if others follow. Note that this was a very relaxed situation and people moved freely at their leisure and probably only rarely as fast as they would have been able to.

\section{Discussion}

\subsection{Comparison to Earlier Studies}

In comparison to various earlier measurements the walking speeds measured on the Expo stairway are quite small, yet they results for the short stairway is in agreement with the literature.

The many single studies typically measure different walking speeds with respect to one variable: conditions (comfortable, normal, dangerous) (Predtetschenski and Milinski, 1971); slope and age (Fruin, 1971); narrow/wide stairs (Frantzich, 1996); age, motivation, and slope (Fujiyama and Tyler, 2004). In addition there are some compilations or "meta studies": Graat (Graat et al., 1999) compiled a list of capacity measurements in which some explicitly deal with upstairs motion and Weidmann (Weidmann, 1992) built an average of 58 single studies and found a horizontal upstairs speed of $0.610 \mathrm{~m} / \mathrm{s}$. Boyce et al. (Boyce et al., 1999) give values for mobility impaired people. There is also a model where the upstairs speed is calculated from the stair geometry (riser and tread) (Templer, 1992).

On the whole the wide variation of results in the literature and in this work shows how much the speed depends on the details of the situation as the age and sex of the persons, the motivation, and the length and slope of the stairway.

\subsection{Caveats}

There are some points one must consider when interpreting the results: 
- The stairs were on the outside with fresh air and good lighting conditions. Depending on what assumes for indoor conditions, this might let one assume that on long indoor stairs walking speeds would be even slower.

- The recording time was in the evening. So one has to assume that most people had already been walking over the Expo area for some hours and were quite tired. This implies that the true walking speeds in an all-day-average would probably be faster.

- On the other hand this situation might also have led to some selection in a way that not only some visitors might have searched more insistently for elevators. But this also can mean that some visitors not aware of the elevators within the building might have passed the pavilion without visiting. This then would have changed the measured mean value compared to the total population toward faster speeds.

- However the stairway is long, this does not mean people moved without breaks. A break could have been used to take a view over the Expo area as well as to recover a bit and move on faster afterward. This again means that the true mean value of walking speeds would be smaller than measured.

- In cases of emergency people are willing to accept higher heart rates when moving, thus they would move faster even on stairs of that length. On long stairways this might only lead to a small increase of the speed. Even moderately increased upstairs speed can be experienced as a significant increase of the effort.

- The reduction of speeds in categories B and C compared to category A must not necessarily be due to density effects. It can also be caused by psychological effects of people belonging to the same group (Klüpfel, 2003).

\subsection{Summary, Conclusions and Outlook}

In this work the results of a measurement of the upstairs walking speeds of a sample of 485 visitors of the Expo 2000 in Hannover were presented and compared to measurements on a much shorter stairway. Nearly all circumstances must have let one suspected that we would find comparatively small walking speeds. While with a total mean horizontal speed of $0.387 \mathrm{~m} / \mathrm{s}$ this proved to be true, one must assume that the true whole-population-average free walking speed on such a stair in such a situation would be even smaller. On the other hand this was an extreme leisure situation; during an emergency higher speeds would probably be possible. The factor of increase, however, would depend on the height to be overcome. Altogether one can assume that the speed distributions measured for this work are sufficient for worst case calculations on stairs with an intemediate or short length and for mean calculations for long stairs.

An interesting observable to measure would be the distribution of break frequencies on long stairs. The number of stairs people are freely willing to move without pausing and the time taken to pause could be a valuable hint for a maximum length of stairs that would pose no problems during evacuations. 
In this study only the (more or less) free speeds on a very long stairway were examined. It would be interesting to measure a) a full fundamental diagram for a given length of a stairway and b) the dependence of the walking speed on the length of the stairway by actaully measuring walking speeds on stairways of different length. Additionally in parallel to motion on a level (Hoogendoorn and Daamen, 2005; Rupprecht, 2005) one could ask for the dependence of the speed or flux on the width of the stairway i.e. the specific flux.

\section{Acknowledgments}

This work has been financed by the "Bundesministerium für Bildung und Forschung" (BMBF) within the Bypass and the PeSOS projects. Concerning the study at the Expo we thank the executing architect at the Dutch pavilion Klaus Becker for his kindly supplying information on the pavilion. Concerning the study at the World Team Cup tournament we thank the tournament director Alexander Jelen for the permission of the study and the executing architect Andreas Kühnel for various support in advance and during the tournament. For that study we also thank Torsten Huisinga, Sabine Knoche, Frank Königstein, Florian Mazur, Andreas Pottmeier, Daniel Weber, Michael Wiedemann all of whom helped with the video recordings.

\section{References}

Boyce, K., Shields, T., and Silcock, G. (1999). Toward the Characterization of Building Occupancies for Fire Safety Engineering: Capabilities of Disabled People Moving Horizontally and on an Incline. Fire Technology, 35:51-67.

DWD (2000). online. http://www.wetterzentrale.de/archive/kl/ $2000 / 20000731$. png link valid as of September 2006.

Frantzich, H. (1996). Study of movement on stairs during evacuation using video analysing techniques. Department of Fire Safety Engineering, Lund Institute of Technology, Lund University.

Fruin, J. (1971). Pedestrian planning and design. Metropolitan Association of Urban Designers and Environmental Planners, New York, USA.

Fujiyama, T. and Tyler, N. (2004). Pedestrian Speeds on Stairs - An Initial Step for a Simulation Model. In Proceedings of 36th Universities Transport Studies Group Conference, Life Science Centre, Newcastle upon Tyne, UK. http: //eprints.ucl.ac.uk/archive/00001241/01/2004_19.pdf, link valid as of September 2006.

Graat, E., Midden, C., and Bockholts, P. (1999). Complex evacuation; effects of motivation level and slope of stairs on emergency egress time in a sports stadium. Safety Science, 31:127-141. 
Hoogendoorn, S. and Daamen, W. (2005). Pedestrian Behavior at Bottlenecks. Transportation Science, 39(2):147-159. doi:10.1287/trsc.1040.0102.

Klüpfel, H. (2003). A Cellular Automaton Model for Crowd Movement and Egress Simulation. $\mathrm{PhD}$ thesis, Universität Duisburg-Essen. http: //www.ub.uni-duisburg.de/ETD-db/theses/available/ duett-08012003-092540/ link valid as of September 2006.

Predtetschenski, W. and Milinski, A. (1971). Personenströme in Gebäuden . Berechnungsmethoden für die Projektierung. Verlagsgesellschaft Rudolf Müller, KölnBraunsfeld. (in German, translation from Russian).

Rupprecht, T. (2005). Untersuchung zur Erfassung der Basisdaten von Personenströmen. Master's thesis, Bergische Universität Wuppertal, FB D - Abt. Sicherheitstechnik. (in German, English publication in preparation) http://www . fz-juelich.de/zam/ZAMPeople/seyfried-teaching link valid as of September 2006.

Templer, J. (1992). The Staircase. MIT Press, Massachusetts, USA.

Weidmann, U. (1992). Transporttechnik der Fussgänger. Schriftenreihe des IVT 90, ETH Zürich. (in German). 